UCRL-JC-118361

PREPRINT

\title{
Crosshole EM for Oil Field Characterization and EOR Monitoring: Field Examples
}

Michael Wilt and Clifford Schenkel, Lawrence Livermore National Laboratory

Carlos Torres-Verdin, Schlumberger-Doll Research

$\mathrm{Ki} \mathrm{Ha}$ Lee, Lawrence Berkeley Laboratory

Hung-Wen Tseng, University of California, Berkeley

This paper was prepared for submittal to the

Sixth UNTTAR International Conference on Heavy Crude and Tar Sands

Houston, TX

February 12-17, 1995

September 1994

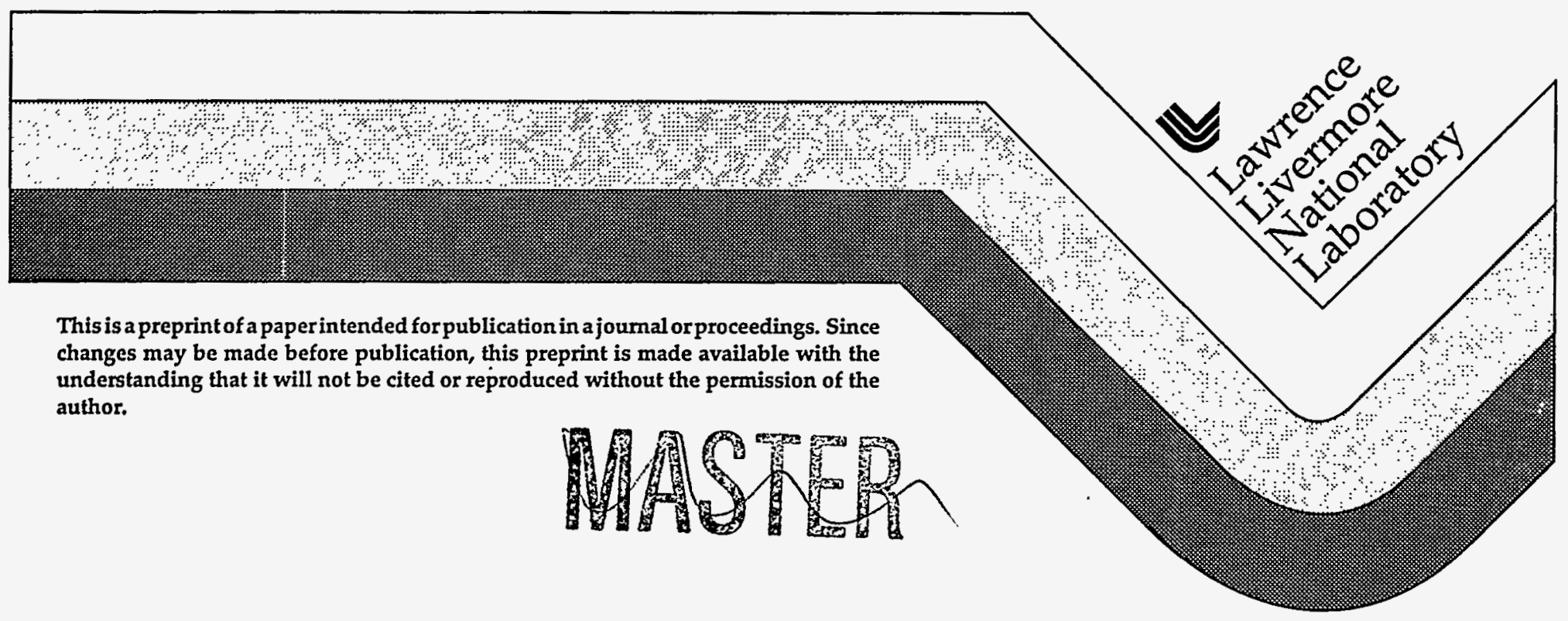




\section{DISCLAIMER}

This document was prepared as an account of work sponsored by an agency of the United States Government. Neither the United States Government nor any agency thereof, nor any of their employees, makes any warranty, expressed or implied, or assumes any legal liability or responsibility for the accuracy, completeness, or usefulness of any information, apparatus, product, or process disclosed, or represents that its use would not infringe privately owned rights. Reference herein to any specific commercial product, process, or service by trade name, trademark, manufacturer, or otherwise, does not necessarily constitute or imply its endorsement, recommendation, or favoring by the United States Government or any agency thereof. The views and opinions of authors expressed herein do not necessarily state or reflect those of the United States Government or any agency thereof. 


\section{DISCLAIMER}

Portions of this document may be illegible in electronic image products. Images are produced from the best available original document. 


\title{
Crosshole EM for Oil Field Characterization and EOR Monitoring: Field Examples
}

\author{
Michael Wilt and Clifford Schenkel Lawrence Livermore National Laboratory \\ Carlos Torres-Verdin Schlumberger-Doll Research \\ Ki Ha Lee Lawrence Berkeley Laboratory \\ Hung-Wen Tseng University of California, Berkeley
}

\begin{abstract}
Crosshole and surface-to-borehole electromagnetic (EM) imaging is applied to reservoir characterization and steam flood monitoring in a central California oil field. Steam was injected into three stacked, eastward-dipping, unconsolidated oil sands within the upper $200 \mathrm{~m}$. The steam plume is expected to develop as an ellipse aligned with the regional northwest-southeast strike. EM measurements were made from two fiberglass-cased observation wells straddling the steam injector on a northeast-southwest profile. Field data were collected before the initiation of a steam drive to map the distribution of the oil sands and then six months after the steam was injected to monitor the progress of the steam chest. Resisitivity images derived from the EM data collected before steam injection clearly delineate the distribution and dipping structure on the target oil sands. Difference images from data collected before and after steam flooding indicate that the steam chest has developed only in the deeper oil sands, and it has preferentially migrated eastward.
\end{abstract}

Surface-to-borehole measurements were useful in mapping the distribution of the major oil sands, but they were insensitive to resisitivity changes in the early stages of the steam flood.

\section{Introduction}

For a number of years, heavy oil has been produced with the aid of steam injection from shallow unconsolidated sands in the San Joaquin Valley of central California. Although most thermal- 
enhanced oil recovery (EOR) projects have been economically successful, many have problems of steam override, steam bypass, and inefficient sweep due to channeling. Thus, developing lowcost, geophysical monitoring methods for EOR has been a priority of operating companies for some time. Seismic techniques have been applied to EOR monitoring with good success, but the high cost of drilling dedicated observation wells and doing surveys deter many developers. Applying electromagnetic (EM) imaging can enhance the quality of the interpretation and allow multiple uses of monitoring wells.

Crosshole and surface-to-borehole EM are excellent methods for monitoring a steam drive due to the high sensitivity of electrical resistivity to changes in temperature and steam saturation. Borehole induction logging measurements in oil fields undergoing EOR have shown that the resistivity typically decreases from 35 to more than $80 \%$ after steam injection $[1,2]$. This is due to the increase in temperature as well as the replacement of high-resisitivity oil by lowresisitivity steam and saltwater injectate.

This short case history illustrates the application of crosshole and surface-to-borehole EM methods for reservoir characterization and EOR monitoring at a central California oil field.

\section{FIELD SYSTEMS}

The EM system operates very similarly to a borehole induction logging tool but with the transmitter and receiver coils deployed in different boreholes (Figure 1). As with any tomographic system, data are collected by positioning transmitter and receiver tools at a number of levels that encompass the area of interest between the boreholes. A typical data set consists of more than 1000 measurements.

The transmitter generates high-power AC signals at the surface and sends them down standard logging cable to be broadcast using a vertical-axis tuned coil. The borehole coil consists of a 
magnetically permeable core (mu-metal or ferrite) wrapped with 100-300 turns of wire and tuned with a capacitor to broadcast a single frequency. We can change this frequency by changing the number of turns (inductance) and/or capacitor in the tool. A surface-based loop transmitter is used for the surface-to-borehole system. This transmitter is operated in the same manner as the borehole source (i.e., tuned with capacitors), but because of the large surface area it is from 10 to 100 times more powerful.

Vertical magnetic fields are detected at the receiver borehole with a commercial borehole coil and the signal is transmitted up the logging cable for measurement with a commercial lock-in detector. The phase reference signal for the lock-in amp is a measurement of the transmitter current, which is carried to the receiver using an optically isolated line. Wheel-type encoders are used to keep track of tool depths, and a portable computer is used to log the data.

With these simple analog systems, we have collected high-quality data at a variety of fields at borehole separations from 10 to $300 \mathrm{~m}$ using frequencies from $100 \mathrm{~Hz}$ to $100 \mathrm{kHz}$ [3]. Data is typically repeatable and reciprocal to 1 percent. We believe the high quality is due to careful attention to isolation and local grounding of the transmitter and receiver sections. Each section has a separate generator for power supply and a local common ground. The transmitter and receiver modules are connected for phase reference and depth control, using optically isolated cables.

Field data are interpreted using.numerical models that fit the EM fields to a two- or threedimensional resisitivity distribution. We use a two-dimensional rectangular mesh code developed at Schlumberger-Doll Research [4], and a three-dimensional rectangular mesh code developed by Lee of Lawrence Berkeley Laboratory. Due to the complexity of the electromagnetic field in a nonuniform medium, a typical data inversion requires more than 12 hours for the two- 
dimensional solution to more than one day for the three-dimensional code on a fast computer workstation.

For the surface-to-borehole data, at present we use only a one-dimensional solution and piece together the best-fit layered models to form a pseudo two-dimensional cross section. Interpretation of these data using two- and three-dimensional models is presently impractical due to the large volumetric coverage. This coverage requires enormous meshes for the numerical models to adequately resolve the subsurface resisitivity structure.

\section{RESERVOIR CHARACTERIZATION AND STEAM FLOOD MONITORING}

Mobil Exploration and Production, Inc. has operated several EOR projects in central California. We are applying EM technology at one of them as a pilot test. Two fiberglass-cased observation wells were drilled along a northeast-southwest profile straddling a steam injector (Figure 2). The wells were drilled for the combined purposes of crosshole EM surveys and repeated temperature and induction (resistivity) logging. Steam was injected at depths of 65, 90, and 120 $m$ into upper, middle, and lower members of a heavy oil sand. The steam injection is expected to follow the natural northwest-southeast regional strike, with the plume developing as an ellipse with the major axis aligned with the natural fractures. The monitoring wells are positioned orthogonal to the regional strike direction so that the crosshole EM data roughly follows the assumption of two-dimensional rectangular geometry.

A cross section derived from borehole induction resistivity logs shows that the higher resisitivity intervals (10-100 ohm-m) typically represent the oil sands; the lower resisitivity units (2-10 ohm$\mathrm{m}$ ) are confining silts and shales (Figure 3). The target sands extend from 60 to $120 \mathrm{~m}$ in three separate intervals. The upper sand is the thickest and most continuous of the three. It begins at a depth of $60 \mathrm{~m}$, has a thickness of up to $20 \mathrm{~m}$, and it dips gently eastward at about $6^{\circ}$. The middle and lower members are thinner and less continuous. The middle member is $3-6 \mathrm{~m}$ thick and lies 
at a depth of approximately $90 \mathrm{~m}$. This unit seems to "pinch-out" near $35 \mathrm{~W}$ and "water-out" somewhere between 35E and borehole 4034 . The lower unit, which lies at about $110 \mathrm{~m}$, is continuous throughout this portion of the field and dips eastward at about $8^{\circ}$. The water table lies at a depth of $160 \mathrm{~m}$, or just below the bottom of the wells.

\section{EM FIELD SURVEYS}

Crosshole and surface-to-borehole EM data were collected in November 1993 and April 1994, before the onset of cyclic steaming and after the initial six months of steaming. Surface-toborehole EM data were collected along profile $\mathrm{A}^{\prime}-\mathrm{A}^{\prime \prime}$, using $10-\mathrm{x}-10-\mathrm{m}$ surface loop transmitters. The surface loops are spaced along profile $\mathrm{A}^{\prime}-\mathrm{A}^{\prime \prime}$, at 10- to 20-m intervals, to a maximum distance of $125 \mathrm{~m}$ from the receiver borehole, 35E. For each transmitter, magnetic field data were collected at 6-m intervals at depths from 10 to $140 \mathrm{~m}$ using frequencies of 1 and $5 \mathrm{kHz}$. Individual surface-to-borehole profiles typically required about one hour; the collection of 16 profiles on line $A-A^{\prime}$ required two days for both frequencies.

Crosshole EM data were collected at two frequencies, 5 and $20 \mathrm{kHz}$, using borehole $35 \mathrm{~W}$ for the transmitter and 35E for the receiver tool. We deployed the tools at depths between 30 and $130 \mathrm{~m}$. Receivers were spaced 4 or $8 \mathrm{~m}$ apart in borehole 35E, and EM data were collected continuously as the transmitter moved between 130 and $30 \mathrm{~m}$ apart in borehole 35.W. A typical crosshole profile required approximately one hour to measure; the entire survey, which consisted of 18 profiles, required two field days to complete for each frequency.

\section{SURFACE-TO-BOREHOLE RESULTS}

A sample surface-to-borehole profile is shown below together with the fit from the onedimensional model in Figure 4. The profile shows the EM field amplitude as a function of depth in borehole 35E using a surface loop transmitter located $65 \mathrm{~m}$ from the well. The 11-layer, onedimensional model is made by initially assuming that the earth consists of 12 layers of equal 
resisitivity, each having a thickness of $10 \mathrm{~m}$. The resisitivity of the layers (but not the thicknesses) was then adjusted by the inversion code until the observed and calculated data matched. A similar plot is produced from each of the 16 loop transmitter sites.

In general, the surface-to-borehole data quality was excellent, with most individual profiles repeating over time to several percent. The.difference in the observed amplitudes in Figure 4 is typical of data collected over long time intervals; that is, the errors increase as the signal gets smaller at greater depths. Notice that the amplitude profiles collected before and after steaming are quite similar. In general, we found that for use in modeling the $1-\mathrm{kHz}$ surface-to-borehole data were not sufficiently sensitive to initial subsurface resisitivity changes due to steam flooding. This is primarily due to the great volume sampled by the measurement and the relatively low frequency used. As the steam flood develops further over time, we expect it to be more visible to surface-to-borehole measurements; at present it is difficult to delineate. At the three transmitter sites adjacent to the steam injection well 5035, the $1-\mathrm{kHz}$ data are much noisier and the $5-\mathrm{kHz}$ data show obvious signal contamination. This may be related to current channeling or grounding along nearby steam pipes and well casings.

An approximate resistivity distribution along $\mathrm{A}-\mathrm{A}^{\prime \prime}$ can be made by plotting the individual layered models beneath the transmitter loops and piecing together the one-dimensional interpretations into a psuedo two-dimensional cross section (Figure 5). The resolution of the section is low, and the "noise" is high, but the position and depth of upper oil sand seem to match the known locations as determined by the borehole induction logs in wells 5035 and $35 \mathrm{~W}$. The one-dimensional interpretation does a much worse job on the lower oil sands, however, the section seems to lose resolution at depth.

The pieced-together cross section as shown above is clearly an intermediate step in the interpretation of surface-to-borehole data. As mentioned previously, it is difficult to apply 
existing two- and three-dimensional inversions to the surface-to-borehole data due to the large numerical meshes required. We expect that this will change as new computational tools are developed and existing codes expanded and adapted.

\section{CROSSHOLE EM RESULTS}

We show a sample crosshole EM profile collected at $5 \mathrm{kHz}$ in Figure 6 . The profile is measured using a fixed receiver located within the upper oil sand at a depth of $60 \mathrm{~m}$ and a continuously moving transmitter with measurements made at $1-\mathrm{m}$ intervals. At first glance, the amplitude data reflect the relative positions of the source and receiver coils; the fields become larger as the source and receiver coils approach the same level and fall off in proportion to the borehole tool separation. The phase data are considerably more sensitive to the resisitivity distribution. For example, the magnitude of the phase data is higher within the higher resistivity oil strata, but it shows pronounced rotation in the lower resistivity shale beds above and below the oil sands. The crosshole field data repeat to approximately $2 \%$; we use this figure as a lower bound in estimating data uncertainty during interpretation.

In Figure 7, we show the 5-kHz amplitude and phase data in contoured form for surveys collected before and after steam injection. In this figure all of the field profiles can be examined on the same plot, and the data from the two surveys can be directly compared. In general, the contour plots have the same general characteristics as the individual profiles; that is, the amplitude data generally reflect the geometric spacing between borehole tools while the phase data are higher in the higher resisitivity oil sands between 60 and $110 \mathrm{~m}$. Notice that while the data collected in 1993 and 1994 are remarkably similar for tool depths above $60 \mathrm{~m}$, they are quite different below this. The data collected in April 1994 show a systematic reduction in both amplitude and phase at depths from 60 to $120 \mathrm{~m}$ compared to the November 1993 measurements. A maximum of more than $25 \%$ difference in the field amplitude is observed together with more than $20^{\circ}$ change in the measured phase. We attribute this to decreases in electrical resisitivity due 
to the steam flooding. The observed difference in the crosshole data is considerably greater than the surface-to-borehole observations. This is primarily due to the closer proximity of the crosshole tools to the steamed zone as well as to the higher frequency applied.

Crosshole EM data were interpreted separately using both of the codes described above. With each code we used a smoothed version of the induction resisitivity logs in boreholes $35 \mathrm{~W}$ and $35 \mathrm{E}$ as a starting guess for the inversion. The two-dimensional code required 20 iterations and approximately 20 hours on an IBM 590-600 workstation to fit the data. The three-dimensional code used a mesh elongated in the strike direction to approximate a two-dimensional geometry. This code required more than two days to fit the data on a similar machine to the IBM workstation. The field data were fit with both inversion codes to within a few percent. The final resisitivity distributions are quite similar for both codes, but the mesh distribution is finer with the two-dimensional code; we therefore show the results only from this code.

We show the subsurface resisitivity distribution between boreholes $35 \mathrm{E}$ and $35 \mathrm{~W}$ before and after steam injection in Figure 8. The darker section in the images represent higher resisitivity zones associated with heavy-oil sands; the lighter areas are lower resisitivity silts and confining shale beds of 1-8 ohm-meters, with an average value of $3 \mathrm{ohm}-\mathrm{m}$. The water table lies at a depth of $130 \mathrm{~m}$. The initial image indicates that the upper oil sands is a thick unit dipping gently eastward. Figure 8 indicates that the middle and lower sands are thinner and more discontinuous between the wells. This image, which is consistent with borehole logs, also shows the upper and lower confining silts to be low-resisitivity units.

The two images shown in Figure 8 are visibly different only at depths below $70 \mathrm{~m}$ in the center of the image. In this portion of Figure 8, the EM data indicate that the resisitivity has decreased significantly due to the steam injection. In all other parts of the image, the before and after data agree to within a few percent. 
In Figure 9 we show a difference image made by subtracting the two previous images. The image shows resisitivity greater than $35 \%$ in the region surrounding the injection hole at depths below $80 \mathrm{~m}$. This indicates that a substantial steam chest has formed in the middle and lower sands, and almost none of the steam has gone into the upper oil sand. Since there is considerable steam injection in the upper perforated zone, this implies that there is some connection between the upper and lower oil sands. Perhaps this is due to a connection from the upper units to these lower units via natural or man-made fractures. The steam also seems to flow preferentially to the east. This is in accord with the induction logs, which indicate that the lower sands are better connected eastward than westward. It is also consistent with increased oil production in well 4034 compared with production before the injection began.

The upper oil sand is clearly having some difficulty accepting steam, at least in the initial phase of steam flooding. This may be explained by the higher oil saturation in this upper unit and the lower pressures that may be applied at the shallower depth. We expect this unit will also develop a substantial steam chest, but it will require more time. We plan to collect EM data in these wells every four to six months within the next year, and we will focus the measurements on this particular region.

\section{CONCLUSIONS}

This case history illustrates the application of crosshole and surface-to-borehole EM imaging to reservoir characterization and steam flood monitoring. The interpretation of the crosshole EM provides the resisitivity distribution between boreholes at a moderate resolution. Difference images from data collected before and after steam flooding clearly indicate the location of the steam chest and can provide insight on the subsurface effective permeability. Surface-to-borehole data are also useful for reservoir characterization; however, the data are not sufficiently sensitive to detect the steam chest, at least in its initial stages of development. 
This work was performed under the auspices of the U.S. Department of Energy by Lawrence Livermore National Laboratory under contract No. W-7405-Eng-48.

\section{ACKNOWLEDGMENTS}

This project was funded by the U.S. Department of Energy through Fossil Energy research *

under Contract W-7405-Eng-48. We would like to thank project manager, Tom Reid for his continued support. We would also like to thank K.M. Deets, Mike Wratcher at Mobil in Bakersfield, and Kim Halbert at Lost Hills for their cooperation and support throughout this project. Field technicians, Don Lippert and Jim Dougherty, from the Geophysical Measurement Facility at Lawrence Berkeley Laboratory, were instrumental in the data collection.

\section{REFERENCES}

1. Mansure, A. J., and Meldau, R. F., 1990, Steam-zone electrical; characteristics for geodiagnostic evaluation of steamflood performance, Soc Pet Eng. Formation Evaluation, September, 241-247.

2. Ranganayaki, R. P, Akturk, S. E., and Fryer, S. M., 1990, Formation resisitivity variation due to steam flooding: a log study: Geophysics, 57, 488-494.

4. Torres-Verdin, C., and Habashy, T., 1993, Crosswell Electromagnetic Tomography, SEG Extended Abstract.

3. Wilt, M. J., Morrison, H. F., Becker, A., and Lee K. H., 1991, Cross-borehole and Surface-toBorehole Electromagnetic Induction for Reservoir Characterization, DOE report $\mathrm{DOE} / \mathrm{BC} / 91002253$.

* LLNL 


\section{FIGURE CAPTIONS}

Figure 1. Schematic diagram for the LLNL/LBL EM system.

Figure 2. Base map for the central California EM study.

Figure 3. Induction resisitivity logs along profile $\mathrm{A}^{\prime}-\mathrm{A}^{\prime \prime}$.

Figure 4. Surface-to-borehole data for a profile $65 \mathrm{~m}$ from the receiver borehole 35E.

Figure 5. Pieced-together one-dimensional inversion of surface-to-borehole data along $A^{\prime}-A^{\prime \prime}$.

Figure 6. Sample crosshole EM data profile at $5 \mathrm{kHz}$ collected between boreholes $35 \mathrm{~W}$ and $35 \mathrm{E}$.

Figure 7. Combined $5-\mathrm{kHz}$ crosshole data set (a) before and (b) after steam injection.

Figure 8. Resisitivity images from crosshole EM data before and after 6 months of cyclic steam injection.

Figure 9. Difference image derived from subtracting the two images in Figure 8. 


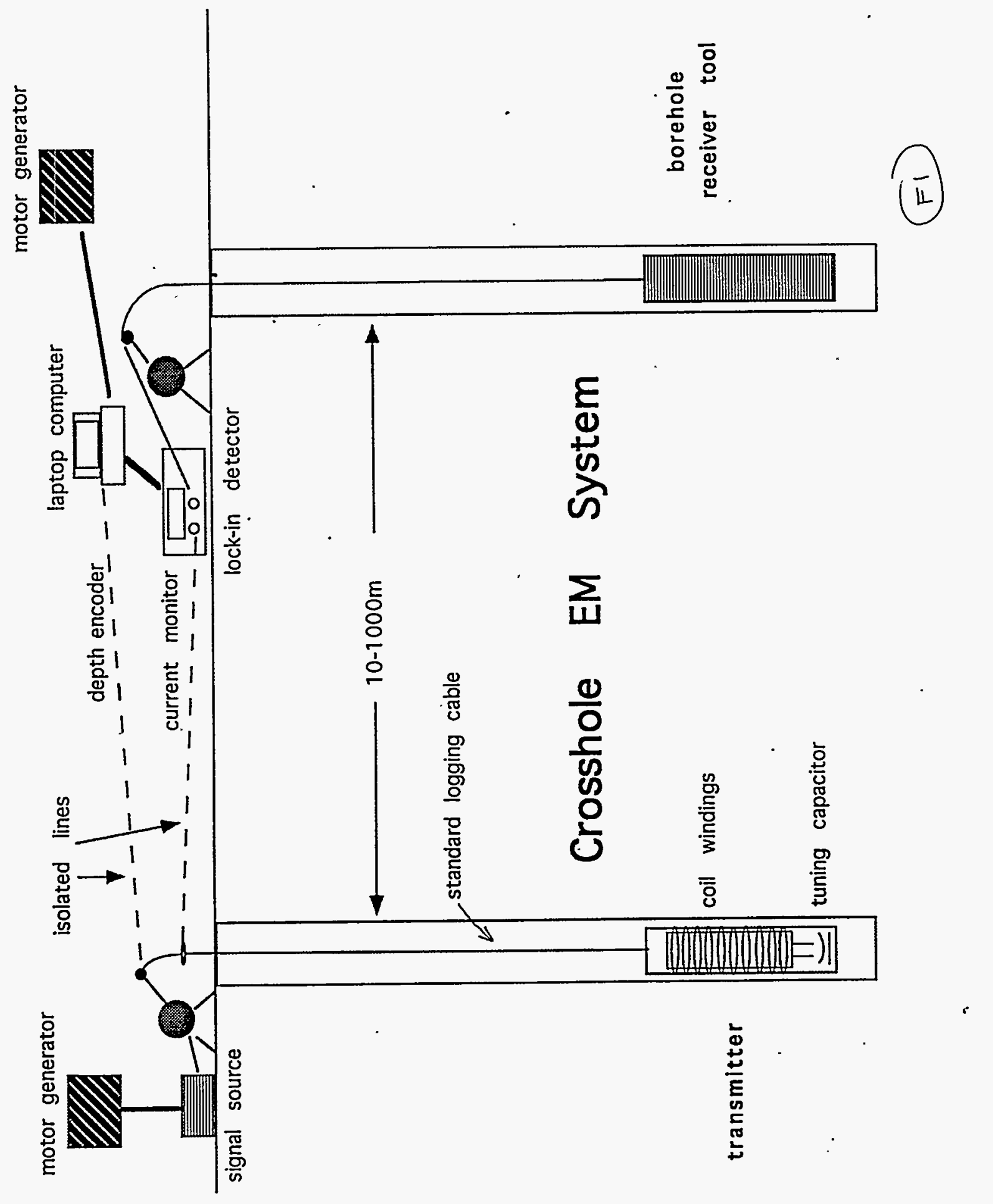


$\Delta$

$\Delta$

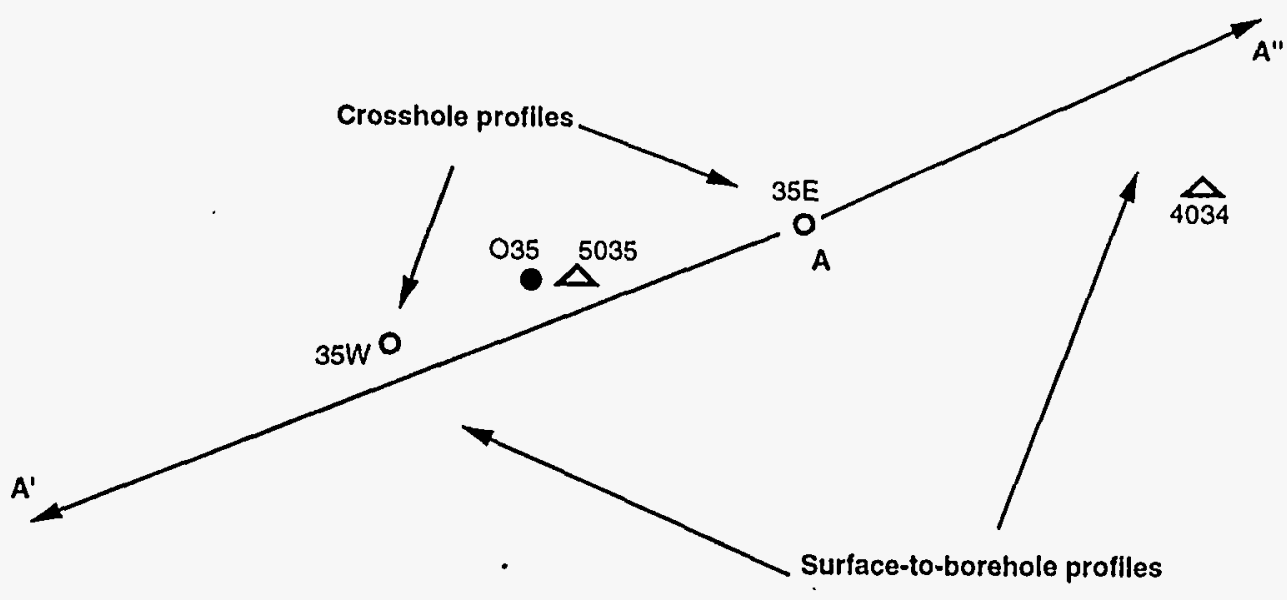

$\Delta$ Steam Injectlon/production well

○ Fiberglass observation well

- Steel-cased observation well

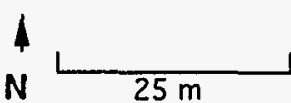

$\Delta$ 

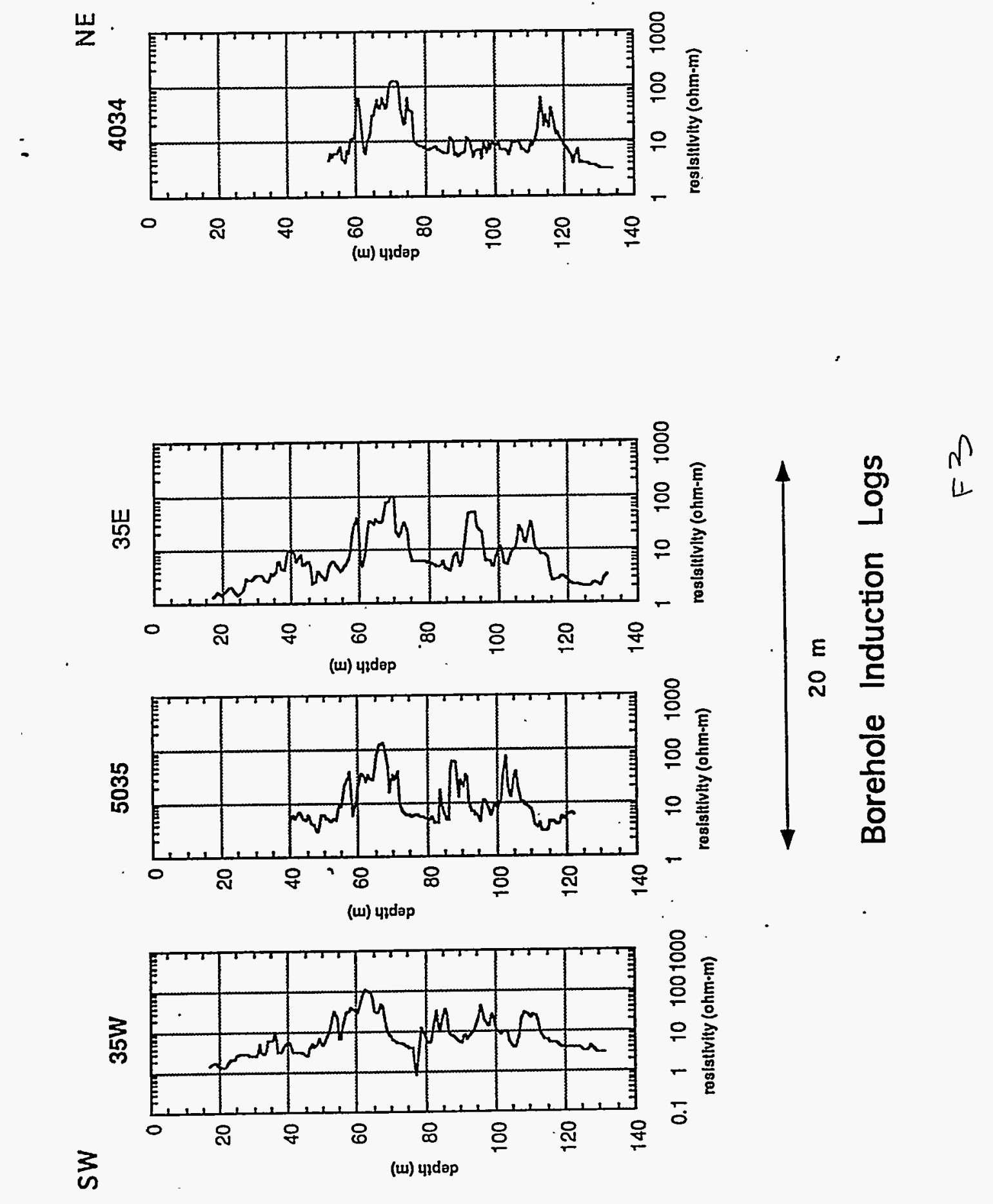


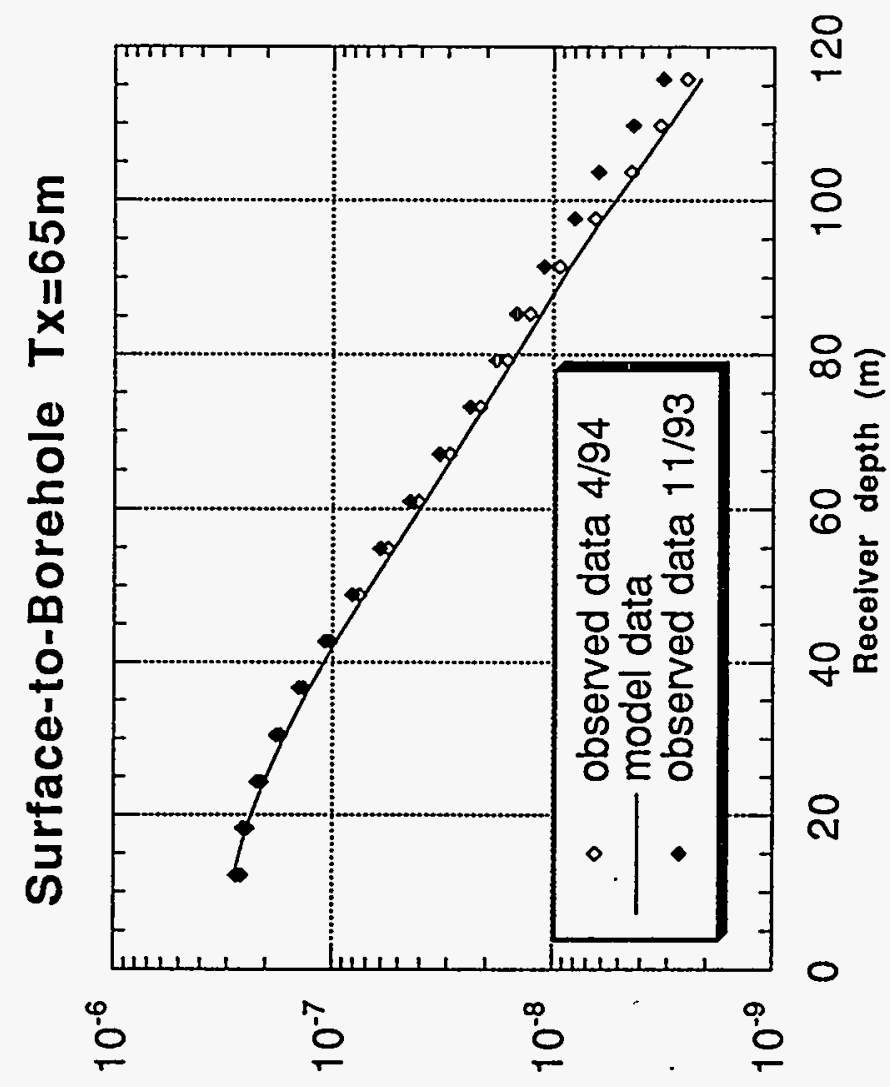

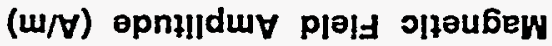




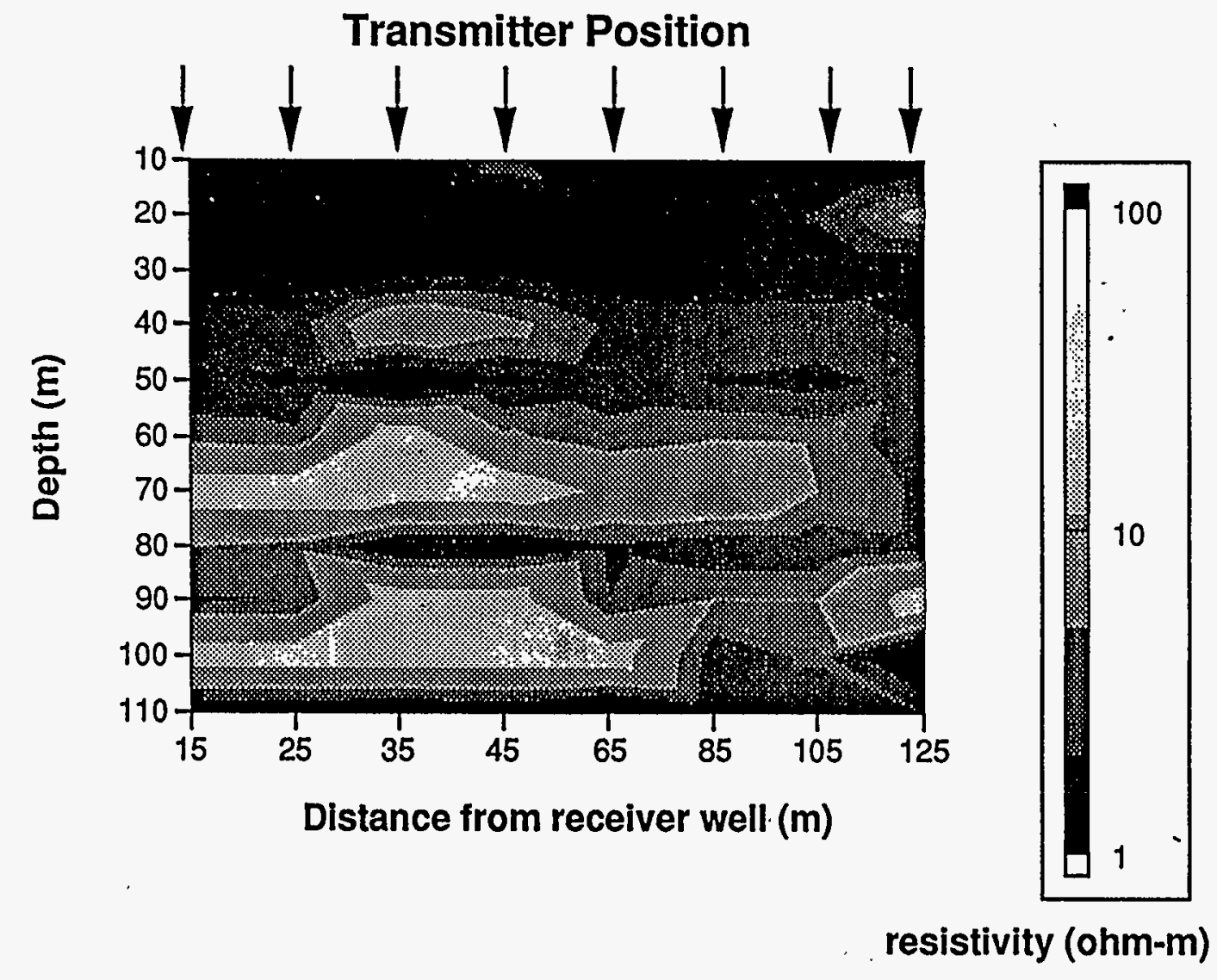

F5 


\section{Lost Hills Amplitude Profile}

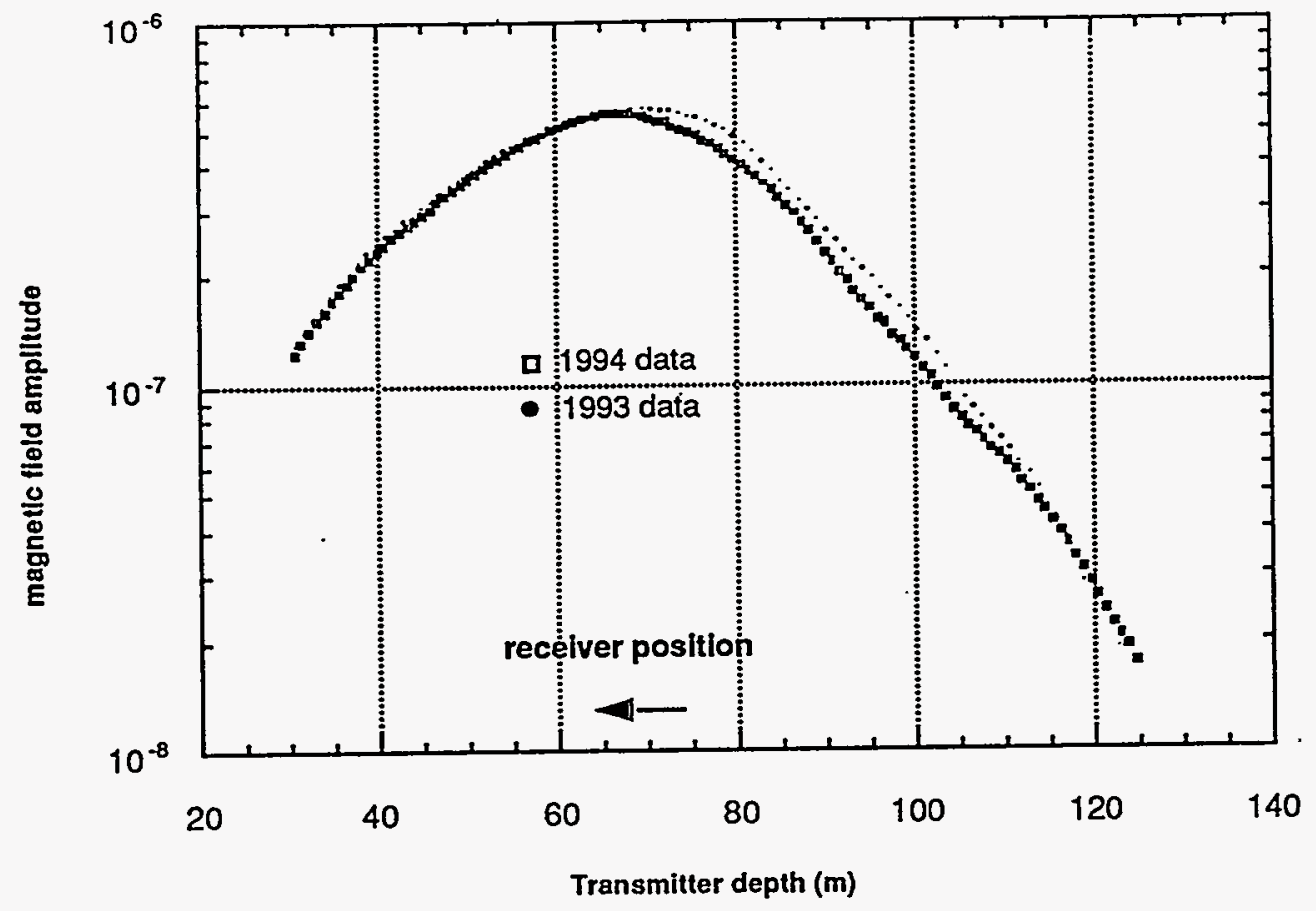

Lost Hills Phase profile

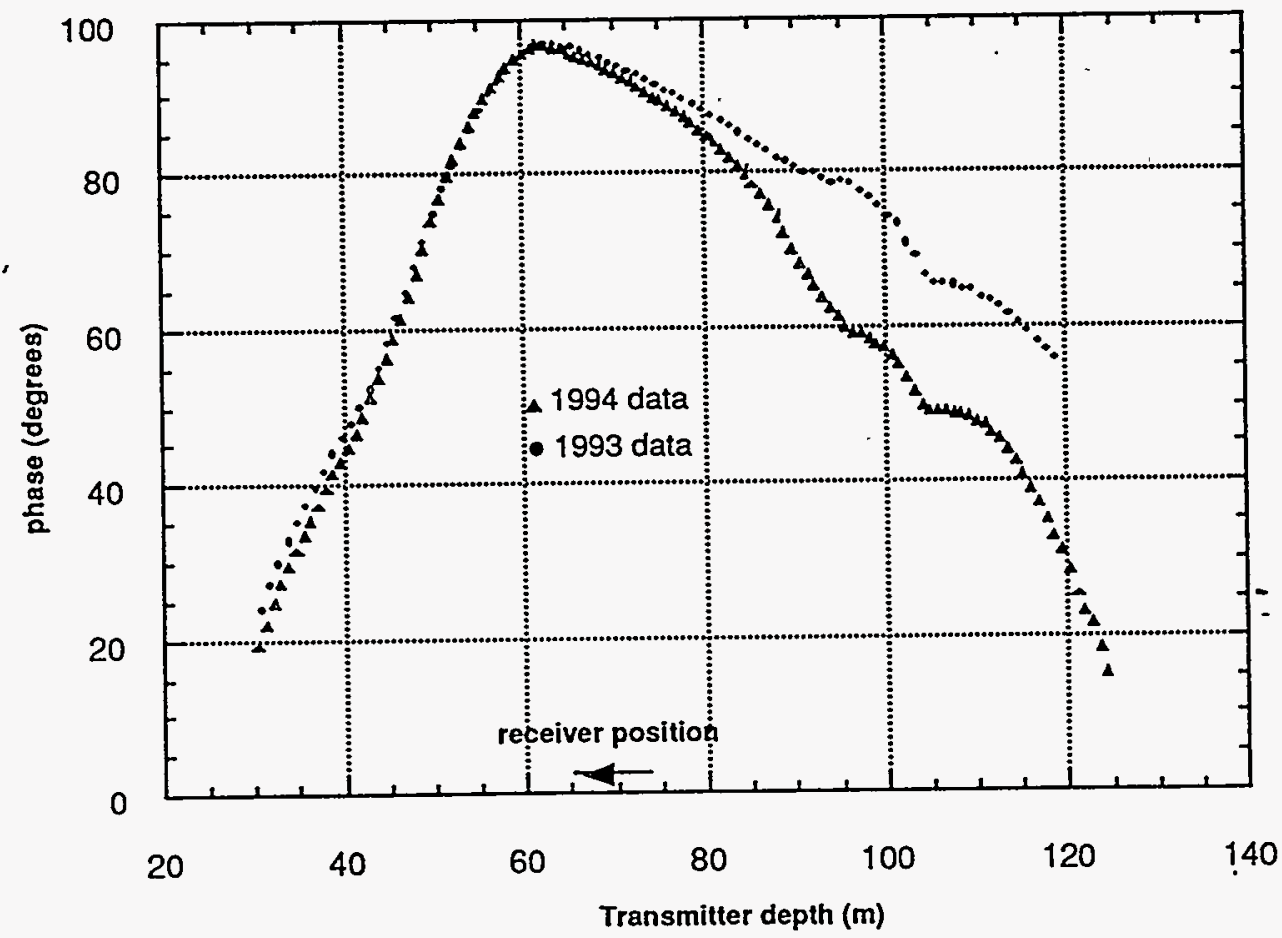

$F G$ 

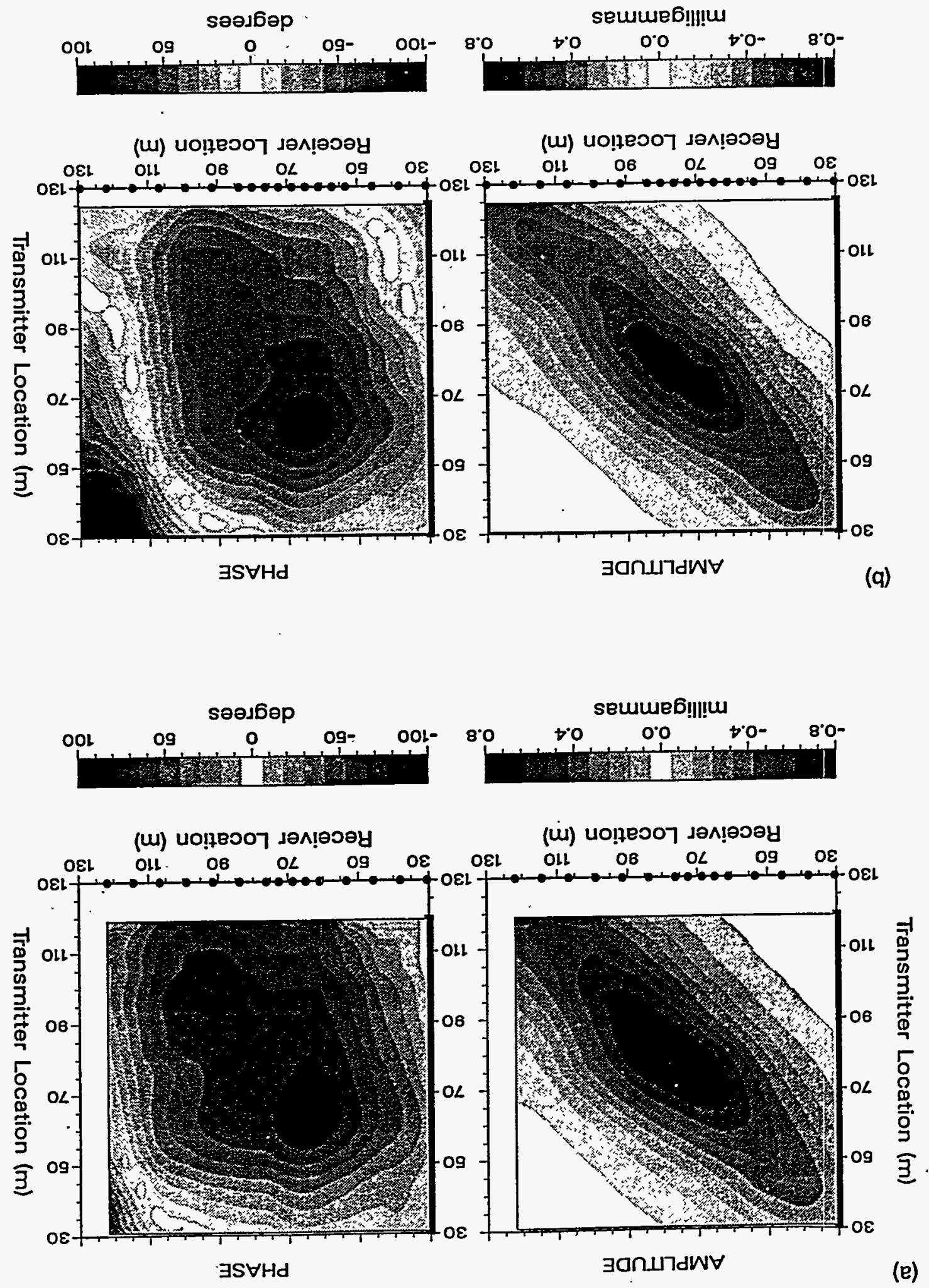


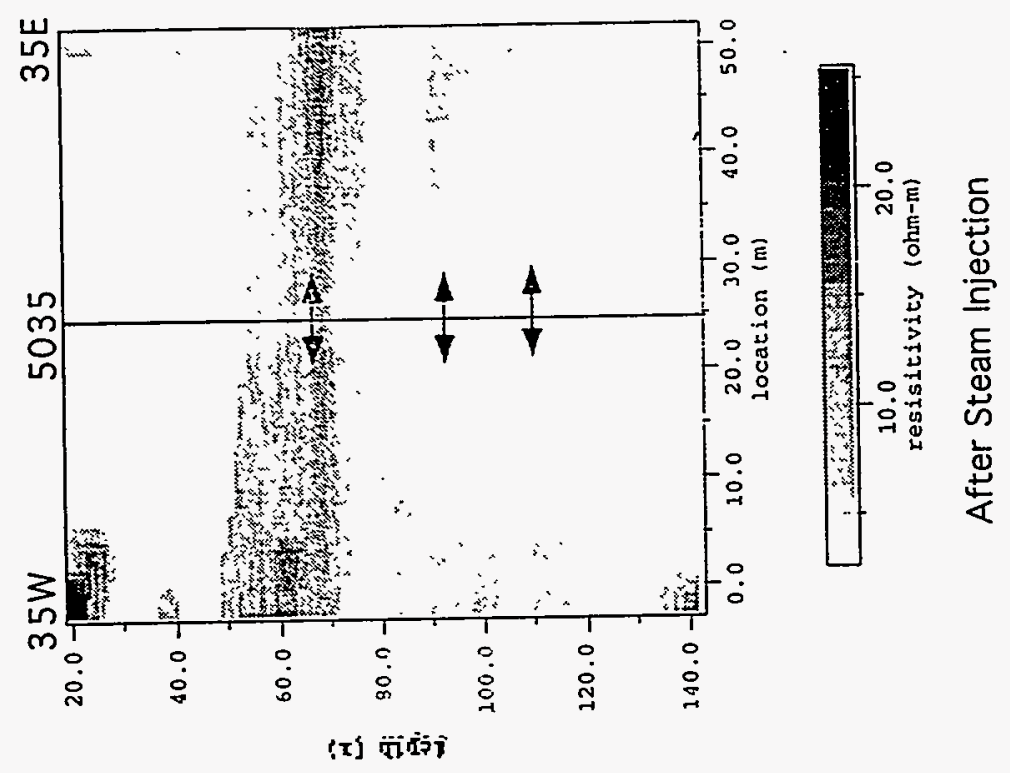

$\infty$
1

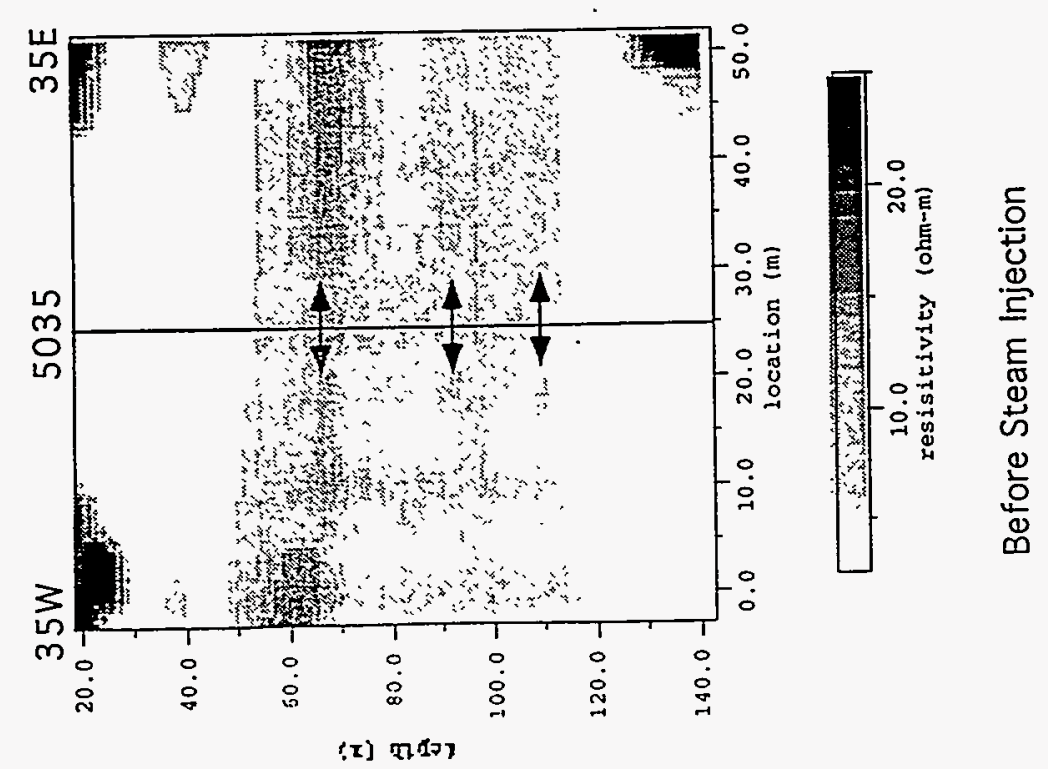




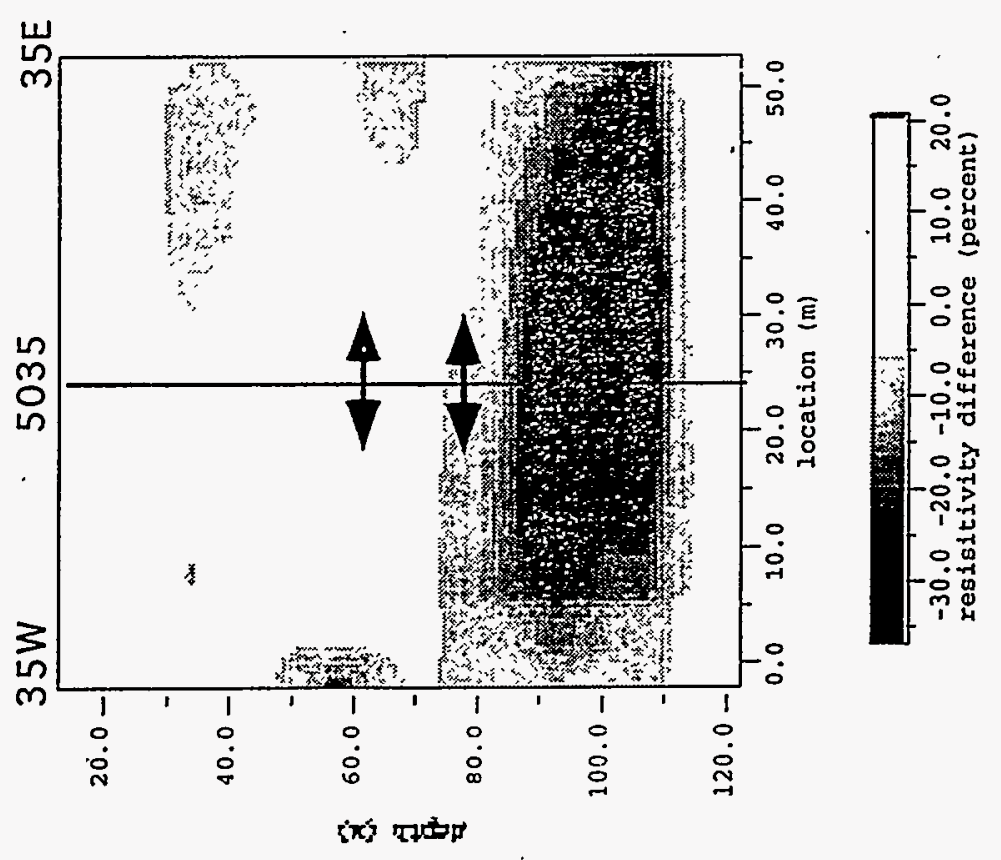

II 